\title{
Low Birth Weight Newborns and Associated Factors at Selected Referral Hospital in Rwanda
}

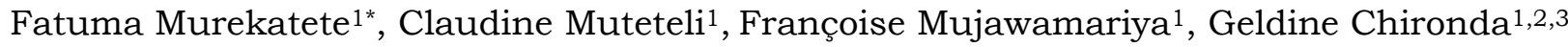 \\ ${ }^{1}$ School of Nursing and Midwifery, College of Medicine and Health Sciences, University of Rwan- \\ da, Kigali, Rwanda \\ ${ }^{2}$ Rory Meyers College of Nursing, New York University, New York, USA \\ ${ }^{3}$ University of KwaZulu Natal, College of Health Sciences, School of Nursing and Midwifery, Dur- \\ ban, South Africa.
}

*Corresponding author: Fatuma Murekatete. School of Nursing and Midwifery, College of Medicine and Health Sciences, University of Rwanda, Remera Campus, 11 KG 47, Kigali, Rwanda. Email: fatumatete@gmail.com.

\begin{abstract}
Background

Low birth weight (LBW) is a major public health problem worldwide that is linked to childhood morbidity and mortality. Newborns considered 'Very LBW' have a high risk of disease and death during infancy. Maternal socioeconomic status, medical factors, and lifestyle are linked to LBW, but these factors remain unknown in Rwanda is unknown.
\end{abstract}

Objective

To describe the factors associated with LBW among newborns at a selected referral hospital in Rwanda.

\section{Methods}

A prospective, cross-sectional design study was used to assess 108 mothers who delivered a low birth weight newborn.

\section{Results}

Mothers had a mean age of 30.6 years, $79.6 \%$ married, $23.1 \%$ primary educated, $50.6 \%$ unemployed, and $61.9 \%$ lived in a rural area. The majority of LBW $(63 \%)$ were in the first category of LBW (2500-1500g), and over a quarter (25.9\%) with Very LBW (VLBW). Mothers were $89.7 \%$ multigravida, and $88.8 \%$ had a previous unsuccessful pregnancy, $81.3 \%$ premature birth, 97.9\% LBW. Over half, 59.8\% had hypertension during pregnancy. Lifestyle included $45.5 \%$ doing strenuous work, and 50.9\% heavy lifting during pregnancy. The level of education $(p=0.009)$, spouse employment $(p=0.017)$, having previous premature baby $(p=0.025)$, previous history of miscarriage $(p=0.028)$, presence of hypertension $(p=0.020)$ and antenatal care visits $(\mathrm{p}=0.025)$ the trimester of miscarriage were significantly associated to type of low birth weight.

\section{Conclusion}

Demographic, pregnancy history and lifestyle factors remain a concern to mothers and neonates born with low birth weight. Educational awareness campaigns among mothers with the factors above are crucial to reduce morbidity and mortality related to low birth weight.

Rwanda J Med Health Sci 2020;3(2):214-224

Keywords: Low birth weight, newborns, maternal risk factors, Rwanda 


\section{BACKGROUND}

Despite the effort made by health agencies to advance the quality of maternal and child health $(\mathrm{MCH}), 15.5 \%$ of all neonates are born with low birth weight (LBW), or less than 2500 grams. Worldwide, 20 million neonates with LBW are born yearly, and $92 \%$ are from developing countries, $70 \%$ in Asia, and $22 \%$ in Africa.[1,2] In nearby East African countries, a study done in Kenya showed that the LBW prevalence was $12.3 \%,[1]$, and $10.6 \%$ in northern Tanzania,[3] whereas the most recent Rwanda Demographic Health Survey (2014-2015) stated an incidence of 6\%.[4]

The progress that a newborn achieves in the first 12 months after birth is vital for survival and a competitive long-life; however, neonatal morbidity and mortality are still severe health challenges globally.[5] Among the causes, LBW is considered significant,[6] with a high probability of disabilities and chronic diseases.[7] A newborn with a weight inferior to 2500 grams, irrespective of gestational age at the birth, would likely have an emaciated appearance, with a lack of subcutaneous tissue (brown fat) and loose skin folds.[8] Other problems include low oxygen levels at birth, respiratory distress syndrome, inability to maintain body temperature, infection, neurologic problems such as intraventricular hemorrhage, gastrointestinal problems such as necrotizing enterocolitis, difficulty feeding and gaining weight, and sudden infant death syndrome (SIDS).[8]

Despite the health sector's efforts to manage LBW newborns, their management is complicated, and consequently, the mortality rate is 20 times higher than that of newborns of normal weight. $[6,7]$ The likely management includes admission to the neonatal intensive care unit (NICU), temperaturecontrolled rooms, and extraordinary feedings, often with a nasal gastric tube for a newborn unable to suck and swallow.[8] The World Health Organization (WHO) recommends three management strategies, including midwifery-led continuity of care (MLCC) models, Kangaroo Mother Care (KMC) and other thermal care, and further clinical interventions, namely, oxygen therapy and other treatments to ease breathing, and feeding sustenance.[9]

The management of LBW is complicated in any country, but it becomes even more challenging in developing countries such as Rwanda. Multifactorial elements play a considerable part and complicate LBW newborn care, such as chronic family poverty leading to food insecurity, limited qualified and skilled healthcare providers (HCPs), insufficient equipment at health facilities, and lack of pregnant women's prosperity leading to future hopelessness. $[1,7,10]$ Fortunately, Rwanda has the political will to strengthen $\mathrm{MCH}$ through different initiatives and strategies. In 2015, the Millennium Development Goals (MDG) era finished, and Rwanda achieved great success. The Sustainable Development Goals (SDGs) began in 2016 by which all health and healthcare system strata are an essential part of implementing strategies directed to accomplish Rwanda's Vision 2020 and SDGs.[11,12] The assessment of maternal risk factors associated with LBW likely provided valuable research to help guide evidencebased practice (EBP) to strengthen $\mathrm{MCH}$ care and meet SDG3 by 2030.

Rwandan four-yearly Summary Report of Maternal and Newborn Deaths stated that $61 \%$ of neonatal mortality included LBW newborns,[13] which indicates, LBW is a significant concern to the Rwandan health sector, especially the HCPs who work with children. Therefore, the purpose of this study is to assess factors associated with LBW among newborns at a selected referral hospital in Rwanda.

\section{METHODS}

\section{Design}

A cross-sectional survey design was used to assess factors associated with low birth weight among neonates. The data collection occurred for two months, from March to April 2019.

\section{Study setting}

The study was conducted in Neonatology, NICU, and Maternity Departments at the Rwanda Military Hospital (RMH). These units are highly equipped with standardized infrastructures and medical equipment for LBW newborns such as hospital birds, incubators, medical ventilator machines, and Continuous Positive Airway Pressure (CPAP) machines. In the NICU at [RMH], about $70 \%$ or more of admissions are LBW newborns.

\section{Study population}

The study population was all mothers who gave birth to an LBW newborn at RMH during the data collection period. The target population was the mother who delivered LBW, whereas accessible population was the mother who delivered LBW, and accepted and consented to participate in the study. 


\section{Participants' recruitment}

The sampling strategy was purposively selected from mothers of LBW neonates in the neonatology, NICU, and maternity department at $\mathrm{RMH}$ during the study period. The sample size was 108 mothers and excluded were mothers with term neonates, twin birth and those refusing to be in the study.

\section{Measures}

The research instrument is the tool that was used to collect and analyze data related to social demographic, medical, and lifestyle factors associated with LBW at RMH. The tool was adapted from the tool validated and used by Gebregzabiherher in the study on the prevalence and risk factors of LBW among term newborns in Adwa General Hospital, Northern Ethiopia.[7] The tool used in Ethiopia was adapted according to our objectives, and further information was obtained from a literature review and the clinical record at the maternity registry. Additional variables from the clinical record included pre-pregnancy weight, height, and weight gain during pregnancy, vaginal and urinary tract infections, and sexually transmitted illness (STI) during pregnancy, and other birth weight. The data collection tool was available in Kinyarwanda and English and was compiled into four sections:

The first section included sociodemographic data; age, marital status, level of education attained, employment status and residence (7 items).

The second section included data related to medical factors; multiparty, successful pregnancies, previous premature baby, previous LBW baby, previous stillbirth, miscarriage, vaginal infections, urinary tract infections (UTI), category of low birth weight and ANC attendance (9 items). This section was scored as, Yes (1 point), or, No (0 points).

The third section included data on maternal lifestyle factors such as work environment, and domestic help, prolonged standing, doing extensive bending, daily meals consumed. These variables were scored as, Yes ( 1 point) or, No ( 0 points). Other variables included daily meals (3 categories); body mass index (BMI) (4 categories); and weight gain status (3 categories) (3 items).

\section{Data collection procedure}

After the university and referral hospital granted permission, the investigator met with the department managers to discuss the best option to access the mothers with LBW newborns. The investigator approached the mothers in the department waiting rooms in the units next to the newborn, and new mothers were seated in order to discuss the study. The mothers were given information about the purpose of the study and other important information, such as confidentially and anonymity, and then invited to be in the study. The mothers who agreed voluntarily to participate in the study read and signed a consent form. The participants were given the questionnaire and answered questions on their own or facilitated by the investigator. The questionnaire took the participant about 15 minutes to complete and then was collected by the investigator.

\section{Data analysis}

Data were cleaned, coded, and entered into SPSS (Version 21) software. Descriptive statistics were used to describe the demographic data, medical, and maternal lifestyle factors, including the low birth weight categories. Inferential Statistics of Chi squared test was used to establish the factors associated with low birth weight. $P$ value was set at 0.05. Data were presented in percentages and frequencies.

\section{Ethical considerations}

Ethical approval from the University of Rwanda, College of Medicine and Health Sciences Institutional Review Board (IRB), and the RMH was obtained before data collection. The investigator ensured the participants that their contribution was voluntary, and they had time to ask questions and obtain accurate answers. It was also explained that the study was part of an academic requirement, and the data collected is for research purposes only. 


\section{RESULTS}

\section{Sociodemographic characteristics}

Table 1. Sociodemographic characteristics $(n=108)$

\begin{tabular}{ll}
\hline Variables & $\mathbf{n}(\%)$ \\
\hline Maternal age (years) & $2(1.9)$ \\
$<18$ & $85(78.7)$ \\
$18-35$ & $21(19.4)$ \\
$>35$ & \\
Marital status & $86(79.6)$ \\
Married & $18(16.7)$ \\
Unmarried with partner & $3(2.3)$ \\
Unmarried not with partner & $1(0.9)$ \\
Divorced & \\
Education level & $14(13.0)$ \\
Post-secondary & $25(23.1)$ \\
Secondary & $8(7.4)$ \\
Technical/vocational & $37(34.3)$ \\
Primary & $24(22.2)$ \\
No formal education & \\
Employment status & $13(12.0)$ \\
Employed & $40(37.0)$ \\
Self-employed & $55(50.9)$ \\
Unemployed & $1(1.0)$ \\
Student & $65(61.9)$ \\
Area of residence & $40(38.1)$ \\
Rural & \\
Urban & \\
\hline
\end{tabular}

The sociodemographic characteristics of participants included a mean age of 30.69 years. The majority were aged 18 to 35 years $(78.7 \%)$, married $(79.6 \%)$, with primary education $(34.3 \%)$, unemployed $(50.9 \%)$, and resided in a rural area (61.9\%). Refer to Table 1.

Table 2. Low birth weight classification

\begin{tabular}{llll}
\hline & & Frequency & Percentages \\
\hline & Low birth weight (LBW) (1500 to 2500grams) & 68 & 63 \\
Type of Low & Very low birth weight (VLBW) (1000grs to 1499grs) & 28 & 25.9 \\
Birth Weight & $\begin{array}{l}\text { Extremely very low birth weight (EVLBW) (less than } \\
\text { 1000grs) }\end{array}$ & 12 & 11.1 \\
& Total & 108 & 100
\end{tabular}

Table 2 reveals information on low birth weight status according to their classification. The majority [68(63\%)] were in the category of Low birth weight, 28(25.9\%) Very low birth weight and only $12(11.1 \%)$ had extremely very low birth weight of less than 1000grs. 
Pregnancy history

Table 3. Pregnancy history $(n=108)$

\begin{tabular}{ll}
\hline Variable & $\mathbf{n}(\%)$ \\
\hline Multiparty & $96(89.7)$ \\
Yes & $11(10.3)$ \\
No & \\
Successful pregnancies & $9(11.3)$ \\
Yes & $71(88.8)$ \\
No & \\
If No, probable causes & $10(14.5)$ \\
Pre-eclampsia & $7(10.1)$ \\
High BP & $23(33.3)$ \\
Premature birth & $9(13.0)$ \\
Caesarean & $2(2.9)$ \\
Stillbirth & $18(26.1)$ \\
Abortion & \\
Previous premature baby & $78(72.2)$ \\
Yes & $18(16.7)$ \\
No & \\
Previous LBw baby & $93(97.9)$ \\
Yes & $2(2.1)$ \\
Previous stillborn baby & \\
Yes & $15(16.3)$ \\
No & $77(83.7)$ \\
Antenatal attendance & \\
At least one antenatal visit & $108(100)$ \\
\hline
\end{tabular}

Table 3 summarizes the findings related to the participants' pregnancy history. The majority $(89.7 \%)$ reported a previous pregnancy, and most were not successful $(88.8 \%)$, mainly due to premature birth or abortion (33.3\% or $26.1 \%$ ), respectively. The premature birth rate was $72.2 \%$, with $97.9 \%$ LBW newborns. However, the stillborn baby was $16.3 \%$. All participants recorded at least one ANC visit. 


\begin{tabular}{ll}
\hline $\begin{array}{l}\text { Maternal lifestyle } \\
\text { Table 4. Maternity lifestyle (n=108) }\end{array}$ \\
\hline Variable & $\mathbf{n}(\%)$ \\
\hline Strenuous work environment & \\
No & $30(54.5)$ \\
Yes & $25(45.5)$ \\
Prolonged standing & \\
No & $62(57.4)$ \\
Yes & $46(42.6)$ \\
Nomestic house help & \\
Yes & $82(75.9)$ \\
Doing heavy lifting & $26(24.1)$ \\
No & \\
Yes & $53(49.1)$ \\
Doing extensive bending & $55(50.9)$ \\
No & \\
Yes & $30(27.8)$ \\
Daily meals consumed & $78(72.2)$ \\
Three & \\
Two & $23(21.3)$ \\
One & $71(65.7)$ \\
Obedy Mass Index group & $14(13.0)$ \\
Overweight & \\
Normal weight & $1(1.3)$ \\
Underweight & $16(20.5)$ \\
Weight gain status & $59(75.6)$ \\
Normal gain & $2(2.6)$ \\
Over gain & $62(73.8)$ \\
\hline & $19(22.6)$ \\
\hline & $3(3.6)$ \\
\hline
\end{tabular}

The maternal lifestyle results described the mothers' behavior during pregnancy or before pregnancy that may have led to giving birth to an LBW newborn (Table 3$)$. Nearly half $(45.5 \%)$ worked in a strenuous environment, and many (42.6\%) reported prolonged standing at work. Half (50.9\%) reported heavy lifting, with extensive bending $(72.2 \%)$. The majority $(75.9 \%)$ reported that they do not have domestic help or anyone that helps with housework. The majority $(78.7 \%)$ reported that they consumed less than three meals on an average day, mostly because they lacked the means to buy food $(59.5 \%)$. The participants' BMI measurement indicated that the majority were of healthy weight $(75.6 \%)$, though some overweight (20.5\%); hence, the weight gained during pregnancy was predominantly $(73.8 \%)$ by underweight. 
Table 5. Factors associated with low birth weight $(n=108)$

\begin{tabular}{lll}
\hline Variables & Low birth weight status & P value
\end{tabular}

\begin{tabular}{|c|c|c|c|c|}
\hline & EVLB & VLB & LBW & \\
\hline \multicolumn{5}{|c|}{$\begin{array}{l}\text { DEMOGRAPHIC VARIABLES } \\
\text { Level of }\end{array}$} \\
\hline education & $4(3.7 \%)$ & 0 & $11(10.2)$ & \\
\hline No formal of & $6(5.6 \%)$ & $8(7.4 \%)$ & $23(21.3 \%)$ & \\
\hline education & $0(0.0 \%)$ & $1(9 \%)$ & $7(6.5 \%)$ & 0.009 \\
\hline Primary & $2(1.9 \%)$ & $5(4.5 \%)$ & $18(16.7 \%)$ & \\
\hline $\begin{array}{l}\text { Technical } \\
\text { Secondary }\end{array}$ & $0(0.0 \%)$ & $5(4.6 \%)$ & $9(8.3 \%)$ & \\
\hline Post-secondary & & & & \\
\hline $\begin{array}{l}\text { Employment } \\
\text { status }\end{array}$ & $5(4.6 \%)$ & $15(13.9 \%)$ & $35(32.4 \%)$ & \\
\hline Unemployed & $6(5.6 \%)$ & $11(10.2 \%)$ & $23(21.3 \%)$ & 0.051 \\
\hline Self-employed & $1(9 \%)$ & $2(1.9 \%)$ & $10(9.3 \%)$ & \\
\hline Employed & & & & \\
\hline $\begin{array}{l}\text { Spouse } \\
\text { employment }\end{array}$ & $1(1.0 \%)$ & $7(6.7 \%)$ & $9(8.7 \%)$ & \\
\hline Unemployed & $7(6.7 \%)$ & $12(11.5 \%)$ & $28(26.9 \%)$ & 0.017 \\
\hline $\begin{array}{l}\text { Self-employed } \\
\text { Employed }\end{array}$ & $4(3.8 \%)$ & $8(7.7 \%)$ & $27(26.0 \%)$ & \\
\hline $\begin{array}{l}\text { Area of } \\
\text { residence }\end{array}$ & $4(3.8 \%)$ & $9(8.9 \%)$ & $27(25.7 \%)$ & 0.824 \\
\hline Urban & $8(7.6 \%)$ & $17(16.7 \%)$ & $40(38.1 \%)$ & \\
\hline
\end{tabular}

Rural

PREGNANCY HISTORY

\begin{tabular}{|c|c|c|c|c|}
\hline $\begin{array}{l}\text { Previous } \\
\text { premature } \\
\text { babies }\end{array}$ & $12(12.5 \%)$ & $23(24.0)$ & $43(44.8 \%)$ & 0.025 \\
\hline Yes & $0(0.0 \%)$ & $2(2.1 \%)$ & $16(16.7 \%)$ & \\
\hline No & & & & \\
\hline $\begin{array}{l}\text { Previous low } \\
\text { birth weight }\end{array}$ & & & & \\
\hline babies & $12(12.6 \%)$ & $24(25.3 \%)$ & $57(60.0 \%)$ & 0.051 \\
\hline Yes & $0(0.0 \%)$ & $1(1.1 \%)$ & $1(1.1 \%)$ & \\
\hline No & & & & \\
\hline $\begin{array}{l}\text { Previous } \\
\text { history of }\end{array}$ & & & & \\
\hline miscarriage & $6(6.3 \%)$ & $9(9.4 \%)$ & $15(15.6 \%)$ & 0.028 \\
\hline Yes & $5(5.2 \%)$ & $16(16.7 \%)$ & $45(46.9 \%)$ & \\
\hline No & & & & \\
\hline $\begin{array}{l}\text { Presence of } \\
\text { hypertensio }\end{array}$ & & & & \\
\hline Yes & $5(4.7 \%)$ & $19(17.8 \%)$ & $40(37.4 \%)$ & 0.020 \\
\hline No & $7(6.5 \%)$ & $9(8.4 \%)$ & $27(25.2 \%)$ & \\
\hline
\end{tabular}




\section{MATERNAL LIFE STYLE FACTORS}

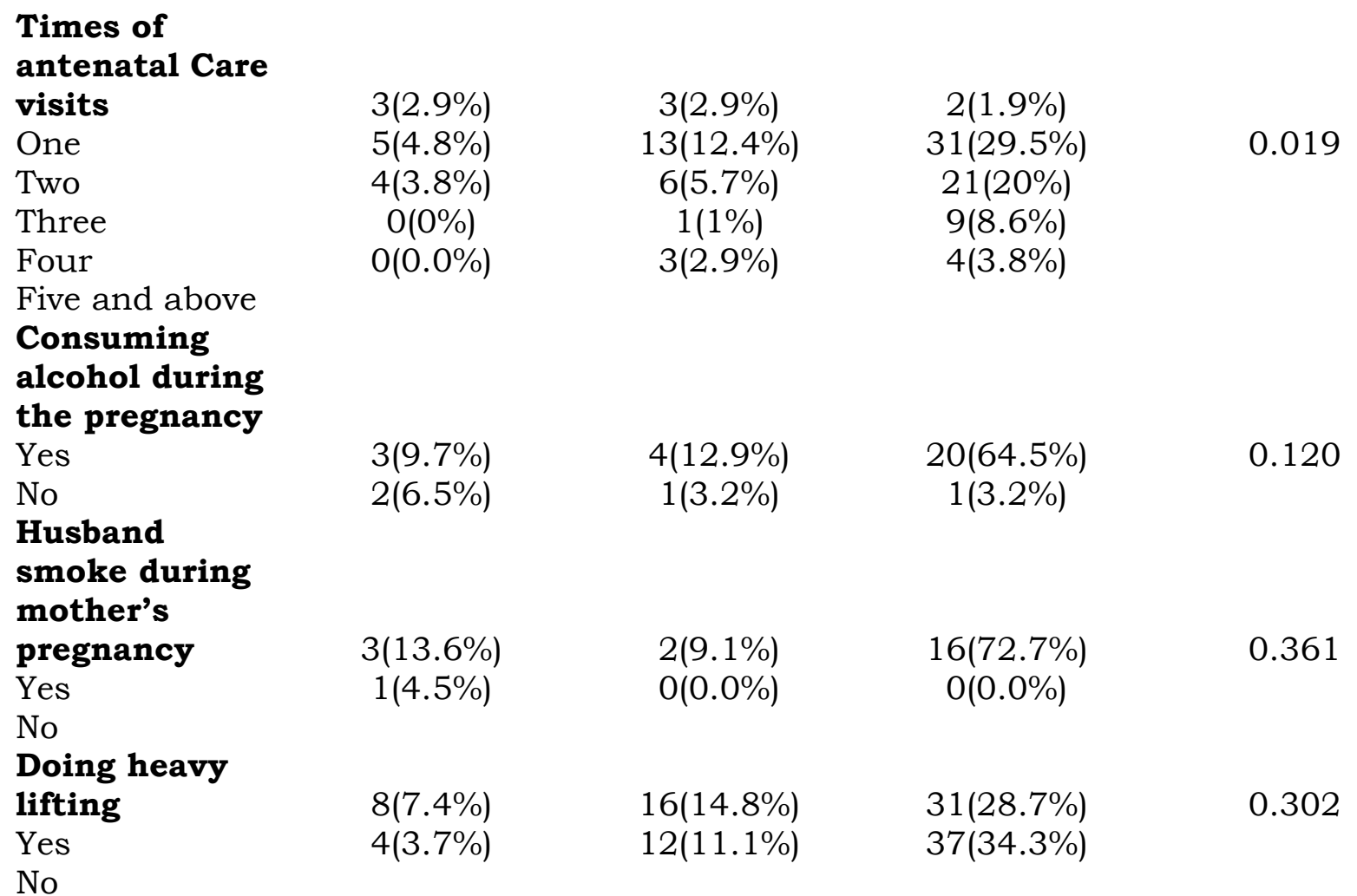

Table5 Highlights information on factors associated with low birth weight. The findings revealed that level of education $(\mathrm{p}=0.009)$, spouse employment $(\mathrm{p}=0.017)$, having previous premature baby $(\mathrm{p}=0.025)$, previous history of miscarriage $(p=0.028)$, presence of hypertension $(p=0.020)$ and antenatal care visits $(p=0.025)$ the trimester of miscarriage were significantly associated to type of low birth weight.

\section{DISCUSSION}

This cross-sectional study of 108 mothers sought to describe the sociodemographic, medical, and lifestyle factors associated with LBW newborns at a referral hospital. Our results assess the many factors that can cause significant child morbidity and mortality.

\section{Sociodemographic characteristics}

This study includes 108 mothers, with the majority aged 18 to 35 years and a mean of 30.69 years (SD 5.41 ), which correlates with other studies, as it is the recommended reproductive age group.[1] In contrast, Jammeh's study had mothers less than 18 years that were 1.8 times more likely to deliver an LBW than mothers older than 35 years. [14] The marital status was dominated by married mothers (79.6\%), and supports the Rwandan government's complaint of legal cohabiting, and similar findings of $90 \%$ married in a study done in Ethiopia.[7]
Though, the family education initiatives like family evening locally known as 'Umugoroba w'ababyeyi, Guardian Angel locally known as 'Malayika Mulinzi', Neighbor watch locally known as 'Ijisho ry'Umuturanyi' Initiatives"[15] may be a solution to alleviate the LBW outcome. The level of education for both partners is significantly associated with LBW. In this study, the majority of mothers $(58.8 \%)$ had a low level, as they had not attended secondary school. This result differs from a study done in Kenya, where the majority attained secondary school.[1]

Mothers with lower formal education were four times more likely to deliver LBW compared to more educated [16] thus, the SDG guide for Rwanda "Ensure inclusive and equitable quality education and promote lifelong learning opportunities for all"[16] will be one of the concomitant initiatives to 
reduce and manage all types of LBW. Thus, the level of education among mothers that delivered LBW significantly influences their employability status $(p=0.001)$. In contrast, Muchemi et al., found that the educational level was dominated by secondary school leavers, and most were selfemployed.[1] Consequently, a lower level of education leads to fewer employment opportunities and income, and further nutritional deficits for the pregnant mother and newborn. Li Tang et al. reported that the mothers' dietary deficiencies relate to intra-uterine growth restriction (IUGR), premature birth $(<37$ weeks) and other defects. [17]

In relation to where the participants lived, the majority (61.9\%) with LBW came from a rural area, similar to Mitao et al., findings.[3] In contrast to findings, Muchemi et al. found that more mothers lived in urban areas,[1] the same as a study done in Tanzania.[3] Thus, this difference may be related to the status of the hospital in which the study has been taken place.

\section{Medical status of mother delivered LBW}

The gravidity of the mother is a key element to illustrate the factors associated with LBW type. Thus, the majority of mothers who delivered LBW are multiparous $(89.7 \%)$, contrary to the study by Pawar et al., which found primiparous higher,[6] and Jammeh 2.5 times more likely to deliver an LBW baby than multiparous.[14]

Our findings revealed that the majorities $(88.8 \%)$ of pregnancies were unsuccessful, and the most common causes of LBW were premature birth, abortion, pre-eclampsia, and HTN. These findings are similar to other studies, $[17,18,21]$ but contrary to a study done by Momeni et al.[22] Furthermore, miscarriage was also among the medical factors associated with LBW, as about a third reported at least one $(31.2 \%)$ or two or more miscarriages $(35.7 \%)$ This finding is lower than a study done in Kenya, where $79.2 \%$ of unsuccessful pregnancies were due to miscarriage.[18]

In this study, participants reported many medical factors. About half (50.9\%) reported that they suffered a UTI in pregnancy and particularly in the $3^{\text {rd }}$ trimester $(49.1 \%)$. Furthermore, many suffered from vaginal infections $(45.4 \%)$, particularly in the $2^{\text {nd }}$ trimester. Other studies $[21,23]$ show genitourinary tract infections related to the LBW outcome.

Furthermore, other maternal factors were reported and possibly related LBW outcomes, such as HTN
(59.8\%), lower backache (51.5\%), vaginal bleeding $(13.2 \%)$, pelvic pressure $(50.5 \%)$ pain when urinating $(47.5 \%)$ and abdominal pain $(45.9 \%)$. Thus, other studies link LBW to these maternal diseases.[1,6,18,21]. The study findings showed that the majority of LBW (63\%) were in the first category of LBW (2500-1500g), and over a quarter $(25.9 \%)$ with Very LBW (VLBW). Thus, this proportion is higher than the $1 \%$ VLBW in a study done in Italy.[19]

The VLBW infant (1000g to $1499 \mathrm{~g}$ ) is more likely to die than LBW in the first category,[20] and the Rwandan community is required to strengthen the $\mathrm{MCH}$ program in order to reduce the burden of VLBW newborns. This difference may be related to socioeconomic factors, our findings are from a poor area, whereas Italy is a developed country. Our findings revealed that all participants recorded at least one ANC visit, which was higher than the $89 \%$ in a study done in India,[2] and $94 \%$ in a study in Kenya.[18] These figures show that the Government of Rwanda has strengthened the power of the $\mathrm{MCH}$ campaign.

\section{Maternal lifestyle of mother delivered LBW}

The maternal lifestyle is another key element positively or negatively influencing the pregnancy outcome. Though, the bivariate analysis revealed that the physical activities are significantly correlated to the medical status of pregnant mothers, which influences pregnancy outcomes, similar to other studies.[17,24] Thus, having extensive bending activities are moderately negative correlated $(\mathrm{r}=-0.3, \mathrm{p}=0.005)$, and weak positively correlated $(\mathrm{r}=0.2, \mathrm{p}=0.044)$ to vaginal bleeding. Mothers with a strenuous work environment are moderately positively correlated to lower backache and pelvic pressure $(r=0.4$, $\mathrm{p}=0.005)$ and $(\mathrm{r}=0.3, \mathrm{p}=0.02)$. Heavy lifting and pain when urinating is weakly positively correlated $(\mathrm{r}=0.2, \mathrm{p}=0.035)$, and having a house helper is negatively correlated to pelvic pressure ( $\mathrm{r}=0.3$, $\mathrm{p}=0.02)$. Thus, findings from other studies $[1,21]$ reveal that maternal lifestyle is indirectly related to LBW.

In this study, we found that the majority $(75.6 \%)$ was a healthy weight before pregnancy (BMI=18.5$24.9)$, but many $(73.8 \%)$ had not gained enough weight. The use of micronutrient supplements during pregnancy is not sufficient $(61.9 \%)$ for the highly needed weight gain, particularly when combined with a strenuous work environment. The amount of physical activity, reduced meals, low weight gain, and micronutrient intake, and 
smoking and alcohol usage during pregnancy are all factors to be considered in predicting, prevention and management of LBW.[25] Thus, nutritional status and behavior are key elements to be considered to reduce the burden of LBW.

In this study, smoking and alcohol intake among pregnant women were not common. These findings are similar to a study in Tanzania,[3] and contrary to other studies, which report smoking and alcohol use during pregnancy is associated with LBW.[3,26] Rwanda has made the population aware of the negative consequences of alcohol during pregnancy, smoking on general health, and legal measures to be taken with public smoking in Rwanda. Furthermore, Rwanda is strengthening the family campaign through various local initiatives, such as family evening locally known as "umugoroba w'Ababyeyi", 1000 days of caring for pregnant mothers locally known as "iminsi igihumbi yo kwita k'umubyeyi n'umwana" are current solutions to alleviate LBW.[15]

\section{CONCLUSION}

This study described the maternal sociodemographic status, medical factors, and lifestyle of 108 mothers with an LBW newborn at a referral hospital in Rwanda. Our analysis revealed that both parents' level of education and employment status are significantly associated with the type of LBW. During pregnancy, the majority of mothers with an LBW newborn were involved in strenuous physical activities and low weight gain. The awareness of heavy physical activities during pregnancy should be taken as a major concern. Eight antenatal contacts with an HCP could allow more opportunity to assess pregnant women, and timely interventions could consequently strengthen $\mathrm{MCH}$ in Rwanda.

\section{Contribution of authors}

FM: development of study protocol, data collection, management and analysis, and manuscript writing. $\mathrm{CM}$ and GC: guidance and supervision during the entire study process. All authors read and agreed to the final version of this manuscript and equally contributed to its content and the management of the case.

\section{Conflict of interest}

There is no conflict of interest with the authors of this study.

\section{Acknowledgments}

Thank you to Dr Pamela Meharry for support with this publication through guidance in writing and manuscript development.

\begin{abstract}
This article is published open access under the Creative Commons Attribution-NonCommercial NoDerivatives (CC BYNC-ND4.0). People can copy and redistribute the article only for noncommercial purposes and as long as they give appropriate credit to the authors. They cannot distribute any modified material obtained by remixing, transforming or building upon this article. See https://creativecommons.org/licenses/by-nc-nd/4.0/
\end{abstract}

\section{REFERENCES}

1. Muchemi OM, Echoka E, Makokha A. Factors associated with low birth weight among neonates born at Olkalou District Hospital, Central Region, Kenya. Pan Afr Med J [Internet]. 2015;20:1-11. Available from: http://www.panafrican-medjournal.com/content/article/20/108/full/

2. Kandel KP, Kafle S. Risk factors associated with low birth weight among deliveries at Bharatpur Hospital. Nepal Journals Online. 2017;15:169-73.

3. Mitao M, Philemon R, Obure J, Mmbaga BT, Msuya S, Mahande MJ. Risk factors and adverse perinatal outcome associated with low birth weight in Northern Tanzania: A registry-based retrospective cohort study. Asian Pacific J Reprod. Elsevier (Singapore) Pte Ltd; 2016;5:75-9.

4. NISR. Rwanda Demographic and Health Survey 2014-15. 2016.

5. Safari M, Samiee A, Salehi F, Ahmadi S, Ahmadi $S$. The prevalence and related factors of low birth weight. International Journal of Epidemiologic Research. 2016;3:214-21.

6. Pawar A, Kumar D. Maternal factors associated with low birth weight: a case control study in rural Kerala. International Journal Of Community Medicine And Public Health. 2017;4:3793-5.

7. Gebregzabiherher Y, Haftu A, Weldemariam $\mathrm{S}$, Gebrehiwet $\mathrm{H}$. The prevalence and risk factors for low birth weight among term newborns in Adwa General Hospital, Northern Ethiopia. Obstetrics and Gynecology International . 2017;2017. 
8. Boston Children's Hospital. Low Birthweight in Newborns. 2018.

9. World Health Organization (WHO). Care of the preterm and low-birth-weight newborn. 2018.

10. Wolcott DM, Reitz RL, Weckerly FW. Biological and environmental influences on parturition date and birth mass of a seasonal breeder. PLoS One. 2015;10:1-17.

11. MINECOFIN RWANDA. Rwanda's approach to implementing the SDGs. 2016;310-2.

12. MINECOFIN RWANDA. Your guide to the Sustainable Development Goals (SDGs) in Rwanda. Kigali: Ministry of Finance and Economic Planning; 2015.

13. Khurmi MS, Felix S, Atakilt B, Tatien B, Kayinamura MA, Emmanuel $M$, et al. Newborn survival case study in Rwanda Bottleneck analysis and projections in key maternal and child mortality rates using Lives Saved Tool (LiST). Int J MCH AIDS. 2017;6:93.

14. Jammeh A, Sundby J, Vangen S. Maternal and obstetric risk factors for low birth weight and preterm birth in rural Gambia: a hospital-based study of 1579 deliveries. Open J Obstet Gynecol. 2011;2011:94-103.

15. GoR M. Umugoroba w'Ababyeyi Strategy. 2014.

16. Government of Rwanda. Your Guide to the Sustainable Development Goals (SDGs) in Rwanda. Kigali Rwanda; 2015. p. 2.

17. Tang L, Pan X-F, Lee AH, Binns CW, Yang C-X, Sun X. Maternal lifestyle and nutritional status in relation to pregnancy and infant health outcomes in Western China: protocol for a prospective cohort study. BMJ Open. 2017;7:e014874.

18. Mogire GK. Factors associated with low birth weight deliveries in Pumwani Maternity Hospital, Master of Science Jomo Kenyatta University Hosp Nairobi-Kenya. 2013;1-99.
19. Cavallo MC, Gugiatti A, Fattore G, Gerzeli S, Barbieri D, Zanini R. Cost of care and social consequences of very low birth weight infants without premature-related morbidities in Italy. Ital $\mathrm{J}$ Pediatr. Italian Journal of Pediatrics; 2015;41.

20. Ballot DE, Agaba F, Cooper PA, Davies VA, Ramdin T, Chirwa L, et al. A review of delivery room resuscitation in very low birth weight infants in a middle-income country. Matern Heal Neonatol Perinatol. Maternal Health, Neonatology and Perinatology; 2017;3:9.

21. Golestan M, Karbasi SA, Fallah R. Prevalence and risk factors for low birth weight in Yazd, Iran. Singapore Med J. 2011;52:730-3.

22. Momeni M, Danaei M, Jabbari A, Kermani $\mathrm{N}$, Bakhshandeh $\mathrm{M}$, Foroodnia $\mathrm{S}$, et al. Prevalence and risk factors of low birth weight in the Southeast of Iran. International Journal of Preventive Medicine.2017;0-4.

23. Tellapragada C, Eshwara VK, Bhat $\mathrm{P}$, Acharya S, Kamath A, Bhat S, et al. Risk factors for preterm birth and low birth weight among pregnant Indian women: A hospital-based prospective study. J Prev Med Public Heal = Yebang Ǔihakhoe chi. 2016;49:165-75.

24. Johnson J, Abraham B, Stephenson B, HM J. A clinical study of Suppurative Keratitis. Int J Biomed Res. 2015;6:869-73.

25. Nguyen PH, Sanghvi T, Kim SS, Tran LM, Afsana K, Mahmud $Z$, et al. Factors influencing maternal nutrition practices in a large scale maternal, newborn and child health program in Bangladesh. PLoS One. 2017;12:1-17.

26. Mourtakos SP, Tambalis KD, Panagiotakos DB, Antonogeorgos G, Arnaoutis G, Karteroliotis K, et al. Maternal lifestyle characteristics during pregnancy, and the risk of obesity in the offspring: A study of 5,125 children. BMC Pregnancy Childbirth. 2015;15:4-11. 